\title{
Production of Levulinic Acid from Lignocellulosic Biomass with a Recyclable Aromatic Acid and Its Kinetic Study
}

\author{
Hairui Ji, ${ }^{a}$ Cuihua Dong, ${ }^{\text {a,b }}$ Guihua Yang, ${ }^{\mathrm{a}, *}$ and Zhiqiang Pang ${ }^{\mathrm{a}, *}$ \\ Levulinic acid (LA), a renewable and valuable platform chemical from \\ lignocellulosic biomass, has exhibited major potential in the production of \\ biomaterials and biofuels. This study reports the production of LA from \\ lignocellulose using a recyclable aromatic acid, toluene sulfonic acid ( $p$ - \\ $\mathrm{Ts} \mathrm{OH}$ ), and its reaction kinetics were investigated. The adoption of $p$ - \\ $\mathrm{TsOH}$, which has a special hydrophobic and hydrophilic structure, \\ dramatically improved the yield of $L A$ to a competitive level $(57.9 \pm 4.1 \%)$ at \\ the optimum conditions (reaction temperature $=162{ }^{\circ} \mathrm{C}$, catalyst \\ concentration $=0.95 \mathrm{~mol} / \mathrm{L}$, and reaction time $=64 \mathrm{~min})$. Meanwhile, the \\ kinetics involving the simultaneous conversion of both glucan (the \\ cellulose component) and mannan (the hemicellulose component) to LA \\ were examined. The results indicated that the activation energy values in \\ the reaction kinetics were lower than those in previous studies that used \\ $\mathrm{H}_{2} \mathrm{SO}_{4}$ as a catalyst. Consequently, the maximum yield of LA was easily \\ obtained at a lower temperature $\left(170^{\circ} \mathrm{C}\right)$. The results of this study are \\ important for process modelling applications and the production of LA from \\ lignocellulosic materials.
}

Keywords: Levulinic acid; p-TsOH; Kinetics

Contact information: a: Qilu University of Technology (Shandong Academy of Sciences), State Key Laboratory of Bio-based Material and Green Papermaking, Jinan, 300175, China; b: State Key Laboratory of Pulp and Paper Engineering, South China University of Technology, Guangzhou, 510640, China; *Corresponding authors: zhiqiang8505@126.com;ygh2626@126.com

\section{INTRODUCTION}

Climate change, exacerbated by the consumption of fossil fuels, is driving the search for alternative and sustainable energy sources derived from renewable feedstock. Lignocellulosic biomass, an abundant renewable feedstock, has received considerable attention as a sustainable alternative to produce biofuels and chemicals. One of its promising application prospects is the preparation of high-value chemicals, such as levulinic acid (LA), which is a versatile platform chemical widely used in numerous industries (Mariscal et al. 2016; et al. 2015).

Levulinic acid, a five-carbon molecule with carboxylic acid and ketone functionalities that enable interesting reactivity pathways, has been identified by the US Department of Energy as one of the 12 most promising molecules derived from biomass. As a top platform chemical, it is the building block in the production of many biochemicals, such as succinic acid, resins, polymers, herbicides, pharmaceuticals, flavoring agents, solvents, plasticizers, and anti-freeze agents (Morone et al. 2015). Some LA derivatives can be used for fuels and are excellent biolubricant base stocks. For example, the esterification of LA with C1-C2 alcohols produces levulinic esters that can be used as diesel additives (Fernandes et al. 2012). The $\gamma$-valerolactone from LA can be converted to 
liquid alkenes (ranging from $\mathrm{C} 8$ to $\mathrm{C} 24$ ) that can be blended with gasoline, diesel, and jet fuels (Dhanalaxmi et al. 2016; Han et al. 2017). The new LA-based polyol ester, trimethylolpropane-tri-LA ester, has exhibited superior lubricant properties (Ji et al. 2015). The production of LA from lignocellulose has already attracted considerable attention and it will likely become one of the key steps in biomass refining.

Various acid catalysts have been tested for LA production from lignocellulose. Heterogeneous acid catalysts, such as solid catalysts, have been considered good candidates because of their easy recovery and tailorable properties (Guzmán et al. 2016). However, solid catalysts often suffer from low yields, long reaction times, and difficult recovery from solid residues. Homogeneous acids, such as $\mathrm{H}_{2} \mathrm{SO}_{4}, \mathrm{HCl}$, and others, have long been the more popular catalysts for high LA yields. Nevertheless, homogeneous acids face challenges, as they are difficult to recycle and severely corrode equipment. Compared with these mineral acids, toluene sulfonic acid ( $p-\mathrm{TsOH})$, an organic acid with an aryl group and $-\mathrm{SO}_{3} \mathrm{H}$ function, has exhibited a higher catalytic activity in water for the hydrolysis of cellulosic materials. Moreover, it can be easily recovered from the reaction mixture using commercially proven crystallization technology by cooling the concentrated spent acid solution to ambient temperatures and reused again (Chen et al. 2017; Ji, et al. 2017). It is thus essential to achieve the environmentally sustainable production of LA from lignocelluloses using $p$ - $\mathrm{TsOH}$.

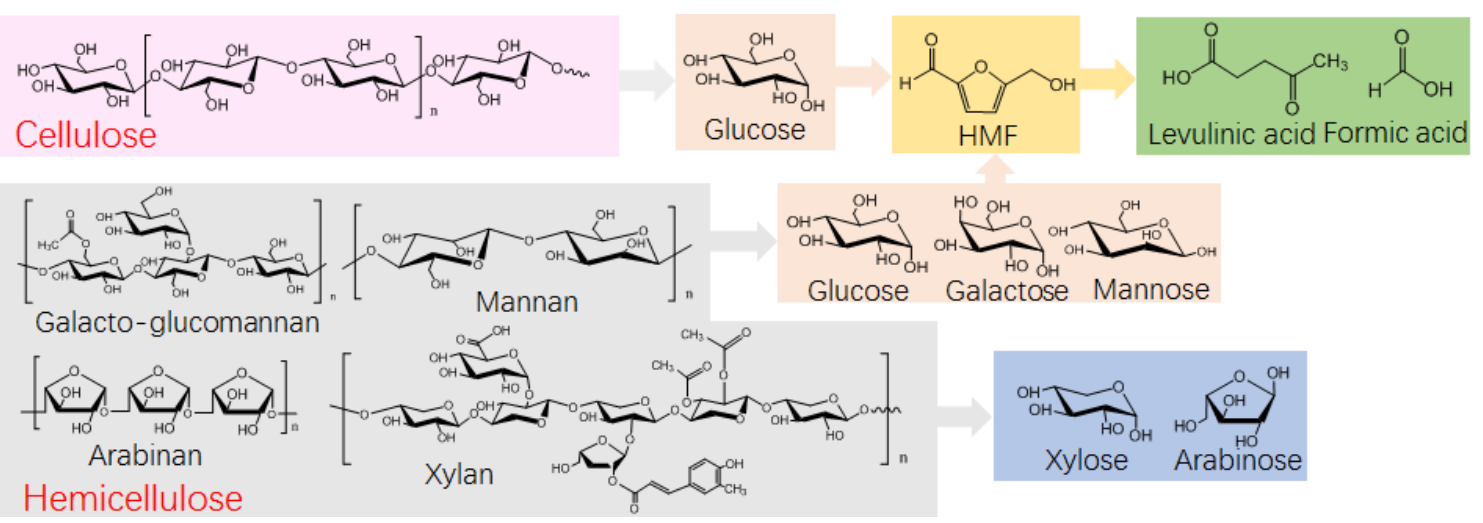

Fig. 1. Proposed conversion pathway of the individual components in the lignocellulosic biomass

At a molecular level, the conversion of lignocellulosic biomass involves a complex reaction pathway (Fig. 1). The polymeric cellulose is typically hydrolyzed into monosaccharides, and the obtained glucose is subsequently isomerized to fructose and dehydrates to form the intermediate product 5-hydroxymethylfurfural (HMF). The 5-HMF is then catalytically rehydrated to form LA and formic acid. Based on this process, various kinetic studies examining LA production through the acid-catalyzed hydrolysis of cellulosic materials have been reported in the literature. However, various sugar polymers in the hemicellulose fraction can also be hydrolyzed to release hexoses. The hexoses follow the same reaction pathway of glucose released from cellulose in the production of LA and formic acid. Consequently, the kinetics of the simultaneous conversion of hemicellulose and cellulose to LA should be considered, especially for mannose-rich lignocellulosic biomass.

The present study reported a high conversion yield of LA from lignocellulose using $p$-TsOH and investigated the reaction kinetics involving the simultaneous conversion of both glucan (cellulose) and mannan (hemicellulose) to LA. 


\section{EXPERIMENTAL}

\section{Materials}

Poplar wood (Populus spp.) powder (glucan $=41.72 \%$; xylan $=16.15 \%$; mannan $=$ $4.29 \%$; lignin $=25.68 \%$; other $=12.16 \%$ ) (Shandong Tranlin Group, Liaocheng, China) with an average size of 20 mesh to 40 mesh was dried to a constant weight at $90{ }^{\circ} \mathrm{C}$ before use. The $p$ - $\mathrm{TsOH} \cdot \mathrm{H}_{2} \mathrm{O}(99 \%$, w\%) was purchased from Shanghai Yuanye Biological Technology Co., Ltd. (Shanghai, China). The $\mathrm{H}_{2} \mathrm{SO}_{4}(95 \%$ to $98 \%$, w\%) and calcium carbonate were supplied by Beijing Chemical Company (Beijing, China).

\section{Batch Dehydration Experiments}

The batch dehydration experiments were conducted in a $100-\mathrm{mL}$ stainless steel reactor. Five grams of wood sample and $50 \mathrm{~mL}$ of different concentrations of $p$-TsOH solution $(0.27 \mathrm{~mol} / \mathrm{L}, 0.55 \mathrm{~mol} / \mathrm{L}$, and $1.10 \mathrm{~mol} / \mathrm{L})$ were combined in the $100-\mathrm{mL}$ stainless steel reactor and heated to the specified temperature $\left(160{ }^{\circ} \mathrm{C}, 170{ }^{\circ} \mathrm{C}\right.$, and $\left.180{ }^{\circ} \mathrm{C}\right)$ with a stirring speed of $200 \mathrm{rpm}$. The reaction times were $30 \mathrm{~min}, 60 \mathrm{~min}$, and $90 \mathrm{~min}$. At the end of each reaction, the spent liquor containing LA and residual solid was separated by a Buchner funnel using filter paper $(15 \mathrm{~cm}$, slow $)$. The obtained LA solutions were analyzed with high performance liquid chromatography (HPLC). The residual solids were dried at $55^{\circ} \mathrm{C}$ in an oven to a constant weight before further component analysis.

\section{Analytical Methods}

The solid samples were hydrolyzed using sulfuric acid with two steps, according to the method from the National Renewable Energy Laboratory (Sluiter et al. 2012). Monosaccharides were measured with a Dionex HPLC system (ICS-5000, Sunnyvale, CA, USA) equipped with an anion exchange column (CarboPac PA20, Thermo Fisher Scientific, MA, USA). The LA and HMF in the spent reaction liquor were determined using a HPLC system (Ultimate 3000, Thermo Fisher Scientific, MA, USA) equipped with a separated column (Aminex HPX-87H, Bio-Rad, CA, USA) and an ultraviolet detector (VWD-3400RS, Thermo Fisher Scientific, MA, USA).

The LA yield with respect to the weight of the raw biomass was calculated as follows:

$$
Y_{\mathrm{LA}}(\%)=\frac{m_{\mathrm{LA}}}{m_{\text {wood }} \times(0.42+0.04) \div 0.90 \times 0.64} \times 100 \%
$$

where $m_{\mathrm{LA}}$ is the total weight of the measured furfural after the reaction $(\mathrm{g})$, assuming no water loss during the reaction; $m_{\text {wood }}$ is the mass of the wood powder used in the reaction (g); 0.42 and 0.04 are the glucan and mannan content in the dry wood (the total amount is 1 ), respectively; 0.90 is the constant for conversion of glucan to glucose; and 0.64 is the constant for conversion of glucose to LA.

For the optimization of the reaction conditions of LA production, response surface methodology was employed to analyze the interaction or relationship between the responses and the variables using the Design-Expert 8 software (Stat-Ease, Inc., MN, USA). A second order polynomial model for the LA yield was obtained by fitting the experimental data.

For the kinetic study, the differential equations involved in the kinetic models were solved numerically using MATLAB (MathWorks, MA, USA). The kinetic parameters were calculated by minimizing the sum of the squares of the deviations between the 
experimental and calculated data using commercial software (Microsoft Excel, Microsoft, Redmond, WA, USA)

\section{RESULTS AND DISCUSSION}

\section{Optimization of the LA Production}

Response surface methodology was used to evaluate the optimization of the reaction conditions and the reciprocal interactions of the reaction factors related to the LA conversion. Table 1 lists the experimental matrix for the design and analytical results of the LA yields. The LA yield $\left(Y_{1}\right)$ was the response to the variables reaction time $\left(X_{1}, \mathrm{~min}\right)$, catalyst loading $\left(X_{2}, \mathrm{~mol} / \mathrm{L}\right)$, and reaction temperature $\left(X_{3},{ }^{\circ} \mathrm{C}\right)$.

Table 1. Experimental Design and Results of LA Production

\begin{tabular}{|c|c|c|c|c|c|}
\hline No. & $\begin{array}{c}\text { Time }-X_{1} \\
(\mathrm{~min})\end{array}$ & $\begin{array}{c}p-\mathrm{TsOH}-X_{2} \\
(\mathrm{~mol} / \mathrm{L})\end{array}$ & $\begin{array}{c}\text { Temperature }-X_{3} \\
\left({ }^{\circ} \mathrm{C}\right)\end{array}$ & $\begin{array}{c}\text { LA } \\
(\mathrm{g} / \mathrm{L})\end{array}$ & $\begin{array}{c}\text { Yield of LA } \\
(\%)\end{array}$ \\
\hline 1 & 30.00 & 0.27 & 160.00 & 0.00 & 0.00 \\
\hline 2 & 60.00 & 0.27 & 160.00 & 1.65 & 5.19 \\
\hline 3 & 90.00 & 0.27 & 160.00 & 3.89 & 12.29 \\
\hline 4 & 30.00 & 0.27 & 170.00 & 4.25 & 13.40 \\
\hline 5 & 60.00 & 0.27 & 170.00 & 8.45 & 26.67 \\
\hline 6 & 90.00 & 0.27 & 170.00 & 13.86 & 43.73 \\
\hline 7 & 30.00 & 0.27 & 180.00 & 3.33 & 10.52 \\
\hline 8 & 90.00 & 0.27 & 180.00 & 7.12 & 22.47 \\
\hline 9 & 60.00 & 0.27 & 180.00 & 11.65 & 36.74 \\
\hline 10 & 30.00 & 0.55 & 160.00 & 4.89 & 15.44 \\
\hline 11 & 60.00 & 0.55 & 160.00 & 9.00 & 28.40 \\
\hline 12 & 90.00 & 0.55 & 160.00 & 17.01 & 53.68 \\
\hline 13 & 30.00 & 0.55 & 170.00 & 8.65 & 27.30 \\
\hline 14 & 60.00 & 0.55 & 170.00 & 14.02 & 44.24 \\
\hline 15 & 90.00 & 0.55 & 170.00 & 16.52 & 52.12 \\
\hline 16 & 30.00 & 0.55 & 180.00 & 11.70 & 36.90 \\
\hline 17 & 60.00 & 0.55 & 180.00 & 16.87 & 53.24 \\
\hline 18 & 90.00 & 0.55 & 180.00 & 15.70 & 49.54 \\
\hline 19 & 30.00 & 1.10 & 160.00 & 7.65 & 24.15 \\
\hline 20 & 60.00 & 1.10 & 160.00 & 17.40 & 54.89 \\
\hline 21 & 90.00 & 1.10 & 160.00 & 15.68 & 49.48 \\
\hline 22 & 30.00 & 1.10 & 170.00 & 12.31 & 38.85 \\
\hline 23 & 60.00 & 1.10 & 170.00 & 15.01 & 47.37 \\
\hline 24 & 90.00 & 1.10 & 170.00 & 14.01 & 44.22 \\
\hline 25 & 30.00 & 1.10 & 180.00 & 14.37 & 45.34 \\
\hline 26 & 60.00 & 1.10 & 180.00 & 13.88 & 43.79 \\
\hline 27 & 90.00 & 1.10 & 180.00 & 12.31 & 38.85 \\
\hline $28^{\#}$ & 120.00 & 1.00 & 153.00 & - & 44.00 \\
\hline $29 \# \#$ & 48.22 & 0.31 & 180 & - & 42.88 \\
\hline
\end{tabular}

\# Reference data from cotton using $\mathrm{HCl}$ as catalyst (Victor et al. 2014);

\#\# Reference data from Gelidium amansii using $\mathrm{H}_{2} \mathrm{SO}_{4}$ as catalyst (Kang et al. 2013)

The results in Table 1 indicated that LA was generated within a range of $0 \mathrm{~g} / \mathrm{L}$ to $17.40 \mathrm{~g} / \mathrm{L}$. A high yield of $54.9 \%$ with a concentration of $17.4 \mathrm{~g} / \mathrm{L}$ was obtained at the conditions of $160{ }^{\circ} \mathrm{C}, 1.10 \mathrm{~mol} / \mathrm{L} p$-TsOH, and $60 \mathrm{~min}$. The experimental data in Table 2 were evaluated via multiple regression analyses and measured for significance using the 
Design-Expert 8 software. The second order polynomial model for the LA yield was as follows:

$$
\begin{aligned}
& Y_{1}=-901.8598+7.53604 X_{1}+487.3968 X_{2}+5.482818 X_{3}-0.919187 X_{1} X_{2}- \\
& 0.031229 X_{1} X_{3}-1.815846 X_{2} X_{3}-0.009089 X_{1}^{2}-67.72491 X_{2}^{2}-0.004717 X_{3}^{2}
\end{aligned}
$$

This model exhibited a good correlation between the observed and predicted results, with a coefficient of determination of 0.9573 (Fig. 2). The experimental values correlated strongly with the predicted values. The results indicated that $95.7 \%$ of the variability in the responses was explained by this model. According to Goh et al. (2010), the high $\mathrm{R}^{2}$ value demonstrated that the model estimated the response within the selected condition range well.

Table 2 presents the analysis of variance (ANVOA) of the LA production for the response surface quadratic model. The results indicated that this model was highly significant, as was evident from the F-test with a low probability value ( $\mathrm{p}$-value $<0.0001$ ) and high F-value (11.05).

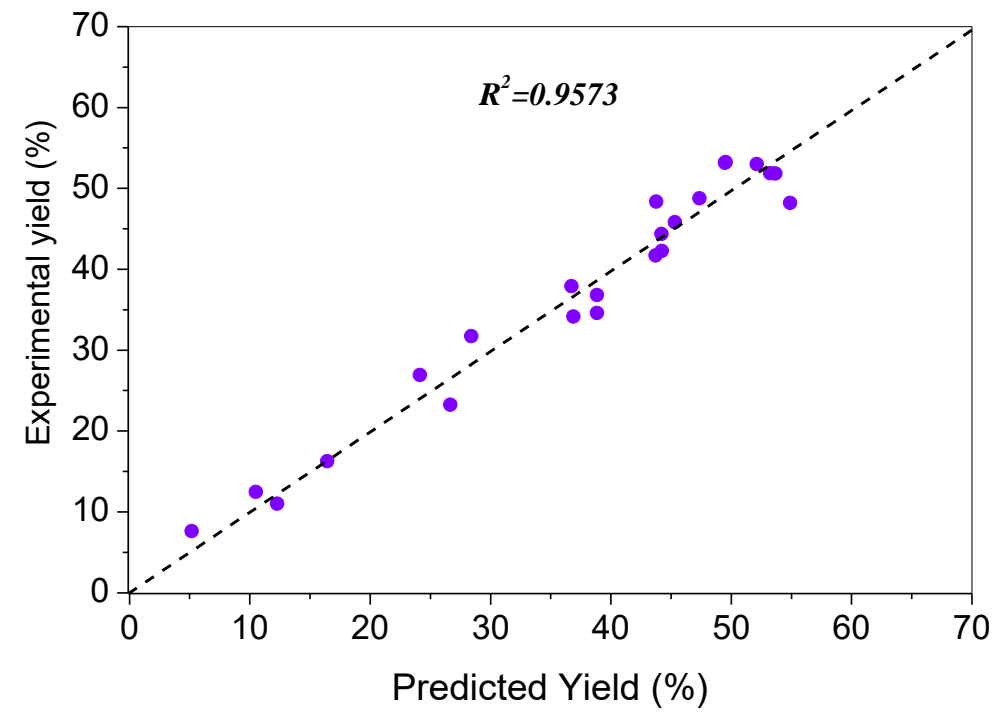

Fig. 2. The correlation between experimental yield and predicted yield of LA

Table 2. ANOVA for the Quadratic Model

\begin{tabular}{|c|c|c|c|c|c|}
\hline Sources & SS & Df & MS & F-value & p-value \\
\hline Regression & 5939.79 & 9 & 659.98 & 11.05 & $<0.0001$ \\
\hline Residual & 1015.52 & 17 & 59.74 & - & - \\
\hline Total & 6955.31 & 26 & - & - & - \\
\hline \multicolumn{7}{|l}{ SS - sum of squares; Df - degrees of freedom; and MS - mean square } \\
\hline
\end{tabular}

Figure 3 demonstrates the effects of the reaction temperature, catalyst concentration, reaction time, and their reciprocal interactions on the LA conversion. These plots were drawn by varying two variables, while the other variable was maintained at the median level. The interaction effects were considered within the variable ranges. The smallest ellipse in the contour plot indicated the optimum values of the variables at the maximum predicted response. Figure 3 a shows the effects of the catalyst concentration, reaction time, and their reciprocal interactions at $162.16^{\circ} \mathrm{C}$. 


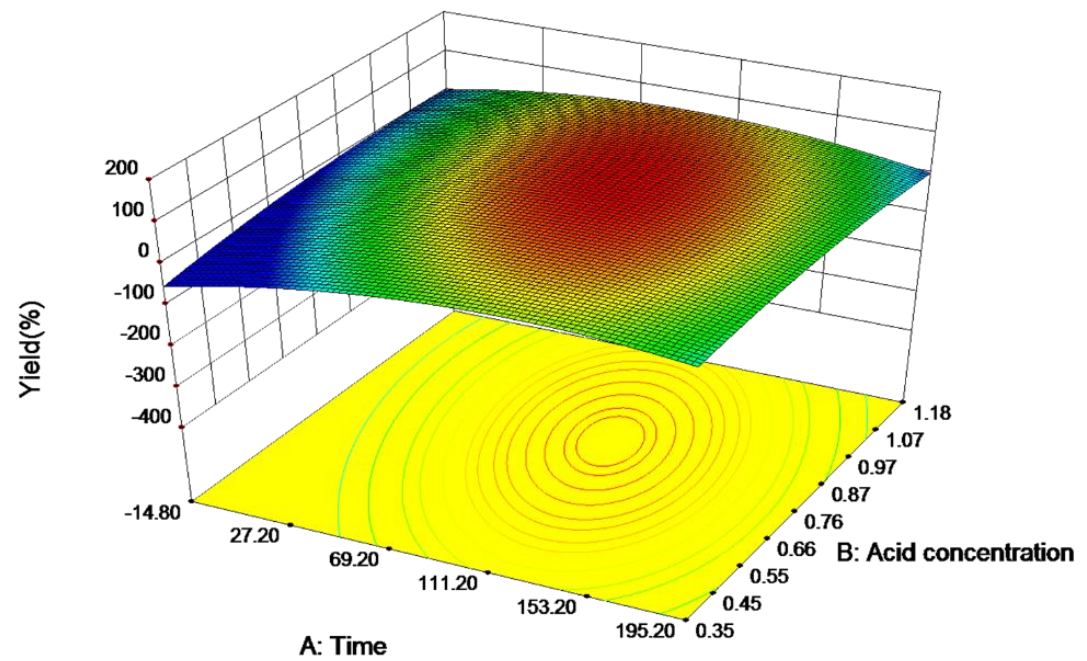

(a)

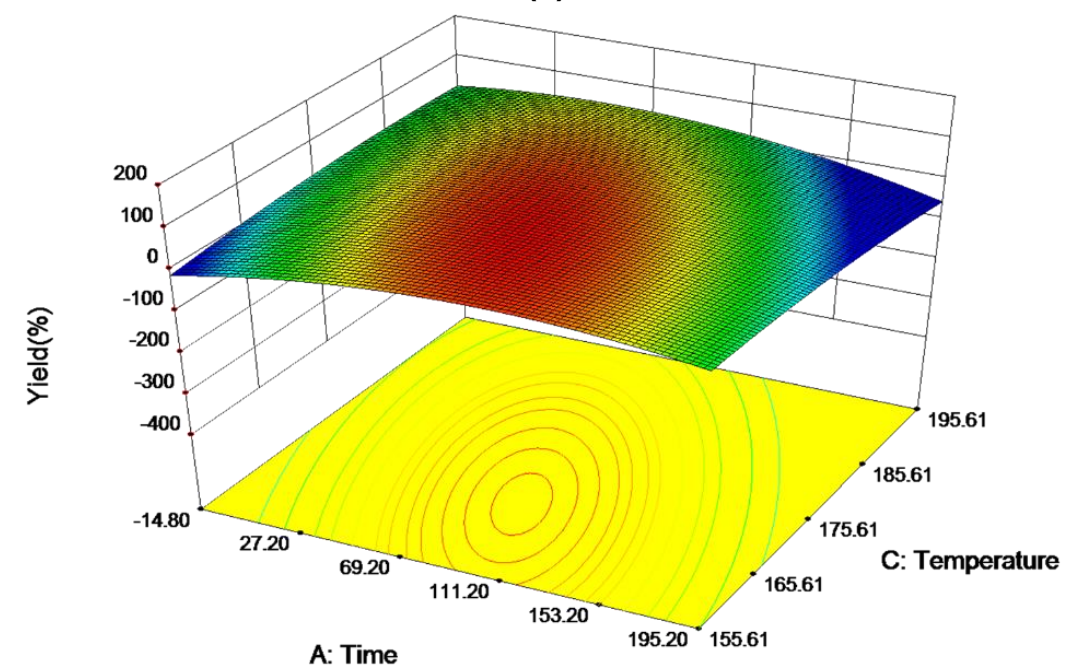

(b)

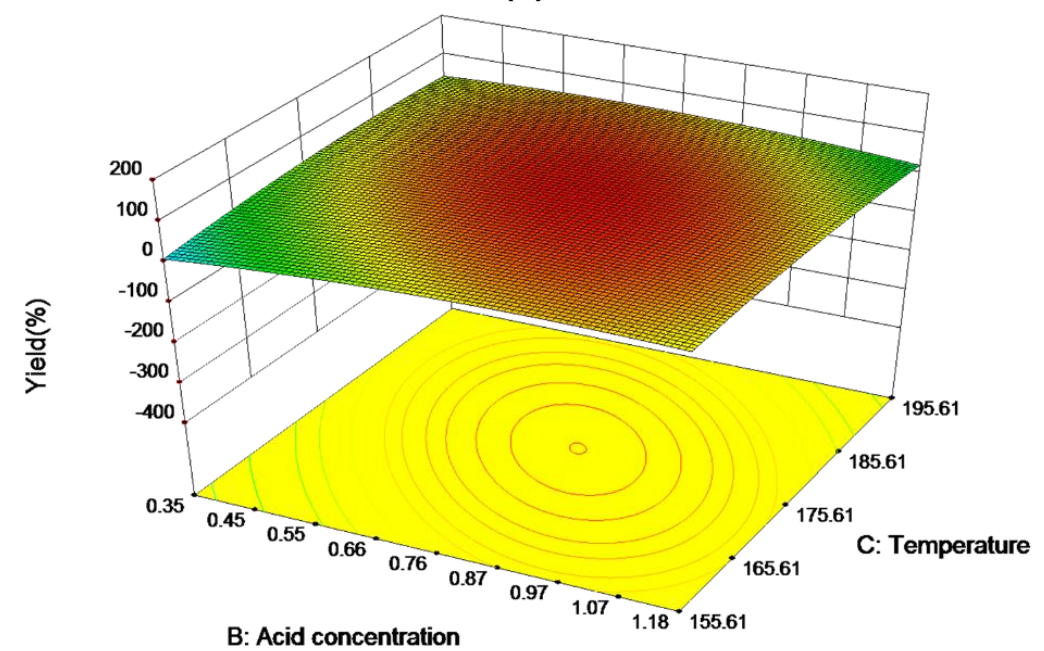

(c)

Fig. 3. Response surface plots representing the effects of the reaction temperature, catalyst concentration, reaction time, and their reciprocal interactions during LA production with a constant (a) temperature, (b) catalyst concentration, and (c) time 
The LA yield linearly increased with an increasing catalyst concentration and as the time neared the optimum conditions. The increase in the catalyst concentration led to a significant improvement in the LA yield. A similar result was found in the study by Jeong and Park (2010) on Gelidium amansii, which stated that the LA conversion increased linearly for a constant reaction time when the catalyst concentration increased. Meanwhile, the LA conversion yield was enhanced with an extended reaction time at a constant catalyst concentration.

Figure $3 b$ shows the effects of the reaction temperature, reaction time, and their reciprocal interaction at the catalyst concentration of $0.95 \mathrm{~mol} / \mathrm{L}$. Increasing the reaction temperature dramatically improved the LA yield. As was mentioned before, it is accepted that elevated temperatures contribute to the acceleration of the reaction rate and conversion efficiency. At high temperature conditions, atoms donate or receive electrons more easily and the chemical reaction rate increases as a result. A higher temperature can also result in a variety of side reactions of glucose and HMF, such as condensation with furfural molecules, resulting in the formation of black resinous products named humins. Therefore, the reaction temperature was an important variable for a high LA yield.

Similarly, the LA yield was enhanced by longer reaction times at a constant temperature. Figure $3 \mathrm{c}$ shows the effects of the reaction temperature, catalyst concentration, and their reciprocal interactions at the reaction time of $64.05 \mathrm{~min}$. By increasing the catalyst loading, the LA yield increased because of the elevated concentration of hydrogen ions available in the reaction system. However, the long reaction time caused degradation of the LA. It was confirmed when examining the $3 \mathrm{D}$ response surface plots that it was unfavorable for a high LA yield when the reaction temperature exceeded the optimum value.

Based on the model analysis, the predicted LA yield was $60.7 \%$ at the optimum reaction conditions $\left(162.2{ }^{\circ} \mathrm{C}, 64.0 \mathrm{~min}\right.$, and $0.95 \mathrm{~mol} / \mathrm{L} p$-TsOH solution). Another test was conducted at the optimum conditions to confirm the predicted LA yield. A high yield of $57.9 \pm 4.1 \%(18.4 \pm 1.3 \mathrm{~g} / \mathrm{L})$ was obtained, which indicated a $4.53 \%$ error between the observed and predicted values. The error with the observed value was within the 5\% significance level. Moreover, the high yield of LA may have been closely related to the special hydrophobic and hydrophilic structure of $p$-TsOH. An interaction force between the hydrophobic tolyl groups and water molecules resulted in strong repulsion, which made it impossible for mineral acids, such as $\mathrm{H}_{2} \mathrm{SO}_{4}$ and $\mathrm{HCl}$, to push the $p$ - $\mathrm{TsOH}$ molecules into the lignocellulosic structure. As a result, the cellulose and hemicellulose were quickly degraded to monosaccharides and corresponding hydrolysates. Overall, the conversion of LA from poplar wood was enhanced with $p$-TsOH under sufficiently severe reaction conditions.

\section{Reaction Scheme and Kinetic Model}

Mannan is a critical component of hemicellulose in poplar wood. The backbone of mannan is comprised of randomly distributed D-glucose and D-mannose structural units linked by $\beta(1 \rightarrow 4)$ glycosidic bonds, which can be substituted with irregularly distributed acetyl groups. Under acidic conditions, polymeric mannan is first depolymerized to mannose and subsequently converted to HMF as the intermediate product. Further conversion of HMF in the presence of the acid catalyst yields LA and formic acid. 


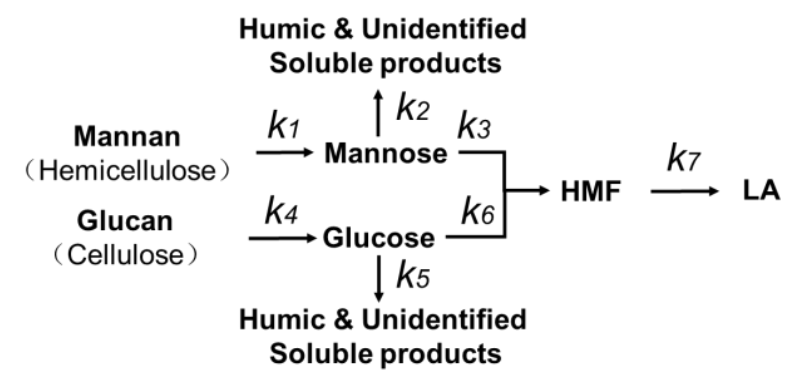

Fig. 4. Reaction scheme for the conversion of poplar wood to LA

Figure 4 shows the reaction scheme used for the development of the kinetic model when producing LA from poplar wood. During acid hydrolysis of the biomass, it was assumed that the different carbohydrates in the biomass (cellulose and hemicellulose) had different reactivities and did not interfere with each other. During the conversion process, the hydrolysis of mannan into mannose and the degradation of glucan into glucose occurred first. Subsequently, mannose and glucose were isomerized and dehydrated to form the intermediate product HMF. However, glucose was not only dehydrated to HMF; it also was decomposed into humins, the undesired polymeric product mentioned above. A dedicated study of the formation of humins from 5-HMF was performed by Girisuta et al. (2013). It was proven that the formation of humins was suppressed at low concentrations of furanic compounds. Therefore, only one parallel reaction from glucose to humins was considered because the HMF concentrations were low throughout the experiments and a negligible amount of humins were formed from HMF.

The reaction rate constants can be expressed through an Arrhenius equation (Eq. 3), which combines the effects of the temperature and hydronium ion concentration,

$$
k=A \cdot \exp \left(-\frac{E_{\mathrm{a}}}{R T}\right) \cdot\left[H^{+}\right]^{\mathrm{m}}
$$

where $\left[\mathrm{H}^{+}\right]$is the $p$-TsOH concentration used in the reaction $(\mathrm{mol} / \mathrm{L}), A$ is an adjustable parameter $(\mathrm{L} / \mathrm{mol}), E_{\mathrm{a}}$ is the apparent activation energy $(\mathrm{J} / \mathrm{mol}), T$ is the temperature $(\mathrm{K})$, $R$ is is the universal gas constant $(8.314 \mathrm{~J} / \mathrm{mol} \cdot \mathrm{K})$, and $m$ is the reaction order of the hydronium ion concentration.

In a batch reactor containing a mixture with a constant density and volume, any change in the concentration of the individual hydrolysate as a function of time was represented by the following ordinary differential equations:

$$
\begin{aligned}
& \frac{\mathrm{d} C_{\text {mannan }}}{\mathrm{d} t}=-k_{1} \cdot C_{\text {mannan }} \\
& \frac{\mathrm{d} C_{\text {mannose }}}{\mathrm{d} t}=k_{1} \cdot C_{\text {mannan }}-k_{2} \cdot C_{\text {mannose }}-k_{3} \cdot C_{\text {mannose }} \\
& \frac{\mathrm{d} C_{\text {glucan }}}{\mathrm{d} t}=-k_{4} \cdot C_{\text {glucan }} \\
& \frac{\mathrm{d} C_{\text {glucose }}}{\mathrm{d} t}=k_{4} \cdot C_{\text {glucan }}-k_{5} \cdot C_{\text {glucose }}-k_{6} \cdot C_{\text {glucose }} \\
& \frac{\mathrm{d} C_{\mathrm{HMF}}}{\mathrm{d} t}=k_{3} \cdot C_{\text {mannose }}+k_{6} \cdot C_{\text {glucose }}-k_{7} \cdot C_{\mathrm{HMF}}
\end{aligned}
$$




$$
\begin{aligned}
& \frac{\mathrm{d} C_{\mathrm{LA}}}{\mathrm{d} t}=k_{7} \cdot C_{H M F} \\
& k_{2}+k_{3}=k_{\text {mannose }} \\
& k_{5}+k_{6}=k_{\text {glucose }}
\end{aligned}
$$

The initial reaction conditions were: $t=0, C_{\text {mannan }}=C_{\text {mannan, } 0}, C_{\text {glucan }}=$ $C_{\text {glucan }, 0} ; C_{\text {glucose }}=C_{\text {glucose }, 0}=0 ; C_{\mathrm{HMF}}=C_{\mathrm{HMF}, 0}=0 ; C_{\mathrm{LA}}=C_{\mathrm{LA}, 0}=0 ;$ Eq. (3-11) could be solved analytically and the following relationships, Eqs. (12-17), were obtained, as shown in supplementary information.

The differential equations involved in the kinetic models were solved numerically using MATLAB. The kinetic parameters were calculated by minimizing the sum of the squares of the deviations between the experimental and calculated data using commercial software with a built-in optimization routine based on Newton's method (Solver). The kinetic parameters are listed in Table 3.

Table 3. Kinetic Parameters for the Acid-catalyzed Hydrolysis of the Poplar Wood to LA

\begin{tabular}{|c|c|c|c|c|}
\hline Rate Constant & $A_{\mathrm{i}}\left(\mathrm{min}^{-1}\right)$ & $E_{\mathrm{i}}(\mathrm{kJ} / \mathrm{mol})$ & $m$ & $\mathrm{R}^{2}$ \\
\hline$k_{1}$ & $5.71 \mathrm{E}+8$ & 75.99 & 0.20 & 0.96 \\
\hline$k_{2}$ & $1.93 \mathrm{E}+11$ & 161.58 & 0.74 & - \\
\hline$k_{3}$ & $1.76 \mathrm{E}+10$ & 90.52 & 1.74 & 0.96 \\
\hline$k_{4}$ & $3.37 \mathrm{E}+13$ & 122.88 & 1.07 & 0.97 \\
\hline$k_{5}$ & $1.68 \mathrm{E}+11$ & 158.57 & 0.93 & - \\
\hline$k_{6}$ & $1.96 \mathrm{E}+12$ & 111.91 & 0.88 & 0.92 \\
\hline$k_{7}$ & $6.62 \mathrm{E}+13$ & 120.52 & 1.06 & 0.89 \\
\hline
\end{tabular}

In this study, the activation energy of the reaction from mannan to mannose was $75.99 \mathrm{~kJ} / \mathrm{mol}$, which agreed with the activation energy value for hemicellulose hydrolysis reported previously by Zhang et al. (2014). The value was also consistent with values reported for the saccharification of hemicellulose from other feedstocks, such as aspen wood $\left(E_{\mathrm{a}}=97 \mathrm{~kJ} / \mathrm{mol}\right)$ (Morinelly et al. 2009) and bagasse $\left(E_{\mathrm{a}}=83.8 \mathrm{~kJ} / \mathrm{mol}\right)$ (Lavarack et al. 2002). However, this reaction had a lower acid concentration order $(0.20)$ than that of the studies mentioned above. By assessing the reaction order, it was concluded that the mannan, as part of hemicellulose, was easily hydrolyzed at a low acid catalyst loading.

For the hydrolysis of cellulose, the activation energy of the reaction from glucan to glucose was $122.88 \mathrm{~kJ} / \mathrm{mol}$, which was lower than that of the reported results for other feedstocks, such as Miscanthus $\left(E_{\mathrm{a}}=188.9 \mathrm{~kJ} / \mathrm{mol}\right)$ (Dussan et al. 2013) and sugarcane bagasse $\left(E_{\mathrm{a}}=144.8 \mathrm{~kJ} / \mathrm{mol}\right)$ (Girisuta et al. 2013), with $\mathrm{H}_{2} \mathrm{SO}_{4}$ as a catalyst. The activation energy for conversion of glucan to glucose indicated a sensitivity to the temperature for glucose formation. When the activation energy is higher, then the temperature needed to promote glucose formation is higher. The results of this study suggested that, when 
compared with studies employing $\mathrm{H}_{2} \mathrm{SO}_{4}$ as the catalyst, lower temperatures were required. The acid concentration reaction order for the reaction from glucan to glucose was 1.07, which was higher than that of the reaction from mannan to mannose. Both the higher activation energy and higher reaction orders with the acid concentration showed that the hydrolysis of cellulose needed more severe conditions to operate compared with that of hemicellulose degradation.

Both mannose and glucose are hexoses and can be dehydrated to HMF in acidic aqueous media at elevated temperatures. The activation energy of $k_{3}$ for the mannose dehydration to HMF was $90.5 \mathrm{~kJ} / \mathrm{mol}$, which was similar to that of $k_{6}\left(E_{\mathrm{a}}=111.9 \mathrm{~kJ} / \mathrm{mol}\right)$. Previous studies reported activation energies for $\mathrm{H}_{2} \mathrm{SO}_{4}$-catalyzed glucose conversion to 5$\mathrm{HMF}$ in the range of $61.1 \mathrm{~kJ} / \mathrm{mol}$ to $161.4 \mathrm{~kJ} / \mathrm{mol}$. This study reported a value of 111.9 $\mathrm{kJ} / \mathrm{mol}$, which was lower than that of most published studies. In the conversion of hexose to HMF, both of mannose and glucose were not dehydrated to only HMF; they were also decomposed to humins. The activation energies for the mannose and glucose conversion to humins $(161.6 \mathrm{~kJ} / \mathrm{mol}$ and $158.6 \mathrm{~kJ} / \mathrm{mol}$, respectively) in this study coincided with those values reported in other studies. The high activation energies of $k_{2}$ and $k_{5}$ implied that the temperature had the most significant effect on this reaction. The hydrolysis reaction at a high temperature would favor the formation of humins and unidentified soluble products. Therefore, the results suggested that the dehydration reaction of glucose would be more profitable for LA formation at low temperatures. The reaction of $k_{5}$ had a higher order (0.93) than that of $k_{6}(0.88)$. This difference indicated that high acid concentrations would promote the reaction of glucose to humins and unidentified soluble products when compared with the conversion of glucose to HMF. Moreover, the reaction rate of cellulose hydrolysis higher, $k_{4}$, than that of glucose degradation to $\mathrm{HMF}, k_{6}$, which in turn led to accumulation of glucose in the reaction liquid.

Levulinic acid is the main product of 5-HMF decomposition. The activation energy for $k_{6}$ was $120.5 \mathrm{~kJ} / \mathrm{mol}$. It was found that the reaction rate of the HMF hydration reaction was faster than those of the other reactions, which strongly suggested that the hydration of HMF to LA was not the rate-limiting step. Once HMF was formed, it was instantaneously converted to LA. As a result, HMF in the reaction mixture required a low concentration, and thus suppressed the formation of the undesired humins. The same explanation has been reported in previous studies (Girisuta et al. 2013). The acid concentration reaction order for $k_{7}$ was 1.06 , which indicated that a high catalyst concentration would facilitate the formation of LA.

The activation energy values for this study were lower than those previously reported in studies that focused on kinetic studies for the conversion of LA from lignocellulose. This highlights the feasibility of converting hexose from cellulose and hemicellulose using $p$ - $\mathrm{TsOH}$, where the reaction can be conducted at a lower temperature. The findings from this study could be useful for process modelling applications and LA production.

\section{CONCLUSIONS}

1. In this study, the production of LA from poplar wood was performed using $p$-TsOH as the catalyst. 
2. The optimum conditions for LA production were determined by the response surface methodology and were a reaction temperature of $162.2{ }^{\circ} \mathrm{C}$, catalyst concentration of $0.95 \mathrm{~mol} / \mathrm{L}$, and reaction time of $64.0 \mathrm{~min}$. The LA yield at the optimum conditions was $57.9 \pm 4.1 \%(18.4 \pm 1.3 \mathrm{~g} / \mathrm{L})$.

3. The kinetics involving the simultaneous conversion of both glucan and mannan to LA were investigated. The results indicated that the activation energy values were lower than previously reported results. The present study used $p$-TsOH as a catalyst, where previous studies have used mineral acid, thus highlighting the feasibility of poplar wood conversion using $p$-TsOH as a catalyst at lower temperatures.

\section{ACKNOWLEDGMENTS}

The authors are grateful for the support of the Natural Science Foundation of Shandong Province (Grant Nos. ZR2017MC007 and ZR2018LB29), R\&D Focus of Shandong Province (Grant No. 2017GGX80102), State Key Laboratory of Pulp and Paper Engineering (Grant No. 201720), Taishan Scholar Project Special Funds, and Foundation of Key Laboratory of Paper Science and Technology of Ministry of Education (Grant No. KF201704).

\section{REFERENCES CITED}

Chen, L., Dou, J., Ma, Q., Li, N., Wu, R., Bian, H., Yelle, D. J., Vuorinen, T., Fu, S., and Pan, X. (2017). "Rapid and near-complete dissolution of wood lignin at $\leqslant 80^{\circ} \mathrm{C}$ by a recyclable acid hydrotrope," Sci. Adv., 3(9), e1701735. DOI: 10.1126/sciadv.1701735 Dhanalaxmi, K., Singuru, R., Mondal, S., Bai, L., Reddy, B. M., Bhaumik, A., and Mondal, J. (2016). "Magnetic nanohybrid decorated porous organic polymer: Synergistic catalyst for high performance levulinic acid hydrogenation," ACS Sustain. Chem. Eng. 5(1), 1033-1045. DOI: 10.1021/acssuschemeng.6b02338

Dussan, K., Girisuta, B., Haverty, D., Leahy, J. J., and Hayes, M. H. B. (2013). "Kinetics of levulinic acid and furfural production from Miscanthus $\times$ giganteus," Bioresource Technol. 149, 216-224. DOI: 10.1016/j.biortech.2013.09.006

Fernandes, D. R., Rocha, A. S., Mai, E. F., Mota, C. J. A., and da Silva, V.T. (2012). "Levulinic acid esterification with ethanol to ethyl levulinate production over solid acid catalysts," Appl. Catal. A-Gen., 425, 199-204. DOI: 10.1016/j.apcata.2012.03.020

Girisuta, B., Dussan, K., Haverty, D., Leahy, J. J., and Hayes, M. H. B. (2013). “A kinetic study of acid catalysed hydrolysis of sugar cane bagasse to levulinic acid," Chem. Eng. J. 217, 61-70. DOI: 10.1016/j.cej.2012.11.094

Goh, C. S., Lee, K. T., and Bhatia, S. (2010). "Hot compressed water pretreatment of oil palm fronds to enhance glucose recovery for production of second generation bioethanol," Bioresource Technol. 101(19), 7362-7367. DOI: 10.1016/j.biortech.2010.04.048

Guzmán, I., Heras, A., Güemez, B., Iriondo, A., Cambra, J. F., and Requies, J. (2016). "Levulinic acid production using solid-acid catalysis," Ind. Eng. Chem. Res. 55(18), 5139-5144. DOI: 10.1021/acs.iecr.5b04190 
Han, J. (2017). "Integrated process for simultaneous production of jet fuel range alkenes and $N$-methylformanilide using biomass-derived gamma-valerolactone," J. Ind. Eng. Chem. 48, 173-179. DOI: 10.1016/j.jiec.2016.12.036

Jeong, G.-T., and Park, D.-H. (2010). "Production of sugars and levulinic acid from marine biomass Gelidium amansii," Appl. Biochem. Biotech. 161(1-8), 41-52. DOI: 10.1007/s12010-009-8795-5

Ji, H., Wang, B., Zhang, X., and Tan, T. (2015). "Synthesis of levulinic acid-based polyol ester and its influence on tribological behavior as a potential lubricant," RSC Adv. 5(122), 100443-100451. DOI: 10.1039/C5RA14366G

Ji, H., Zhu, J. Y., and Gleisner, R. (2017). "Integrated production of furfural and levulinic acid from corncob in a one-pot batch reaction incorporating distillation using step temperature profiling," RSC Adv. 7(73), 46208-46214. DOI: 10.1039/c7ra08818c

Kang, M., Kim, S. W., Kim, J.-W., Kim, T. H., and Kim, J. S. (2013). “Optimization of levulinic acid production from Gelidium amansii," Renewable Energy 54, 173-179. DOI: $10.1016 /$ j.renene.2012.08.028

Lavarack, B. P., Griffin, G. J., and Rodman, D. (2002). "The acid hydrolysis of sugarcane bagasse hemicellulose to produce xylose, arabinose, glucose and other products," Biomass Bioenerg. 23(5), 367-380. DOI: 10.1016/S0961-9534(02)00066-1

Morinelly, J. E., Jensen, J. R., Browne, M., Co, T. B., and Shonnard, D. R. (2009). "Kinetic characterization of xylose monomer and oligomer concentrations during dilute acid pretreatment of lignocellulosic biomass from forests and switchgrass," Ind. Eng. Chem. Res. 48(22), 9877-9884. DOI: 10.1021/ie900793p

Mariscal, R., Maireles-Torres, P., Ojeda, M., Sádaba, I., and López Granados, M. (2016). "Furfural: A renewable and versatile platform molecule for the synthesis of chemicals and fuels," Energ. Environ. Sci., 9(4), 1144-1189. DOI: 10.1039/C5EE02666K

Morone, A., Apte, M., and Pandey, R. A. (2015). "Levulinic acid production from renewable waste resources: Bottlenecks, potential remedies, advancements and applications," Renew. Sustain. Energ. Reviews, 51, 548-565. DOI: 10.1016/j.rser.2015.06.032

Sluiter, A., Hames, B., Ruiz, R., Scarlate, C., Sluiter, J., Templeton, D., and Crocker, D. (2012). "Determination of structural carbohydrates and lignin in biomass (NREL/TP510-42618)," Natl. Renew. Energy Lab.

Victor, A., Pulidindi, I. N., and Gedanken, A. (2014). "Levulinic acid production from Cicer arietinum, cotton, Pinus radiata and sugarcane bagasse," RSC Adv. 4(84), 44706-44711. DOI: 10.1039/C4RA06246A

Zhang, C., Houtman, C. J., and Zhu, J. Y. (2014). "Using low temperature to balance enzymatic saccharification and furan formation during SPORL pretreatment of Douglas-fir," Process Biochem. 49(3), 466-473. DOI: 10.1016/j.procbio.2013.12.017

Article submitted: July 20, 2018; Peer review completed: October 11, 2018; Revised version received: and accepted: November 13, 2018; Published: December 3, 2018. DOI: $10.15376 /$ biores.14.1.725-736 